\title{
The relationship between differentiation of self and satisfaction with life amongst Israeli women: A cross cultural perspective
}

\author{
Aya Biadsy-Ashkar, Ora Peleg* \\ Department of Counseling, The Max Stern Yezreel Academic College, Emek Yezreel, Israel; \\ "Corresponding Author: orap@yvc.ac.il,pelegora@gmail.com, b.aya85@gmail.com
}

Received 10 May 2013; revised 15 June 2013; accepted 20 July 2013

Copyright (C) 2013 Aya Biadsy-Ashkar, Ora Peleg. This is an open access article distributed under the Creative Commons Attribution License, which permits unrestricted use, distribution, and reproduction in any medium, provided the original work is properly cited.

\begin{abstract}
The current study examined the relationships between satisfaction with life and differentiation of self among Jewish and Arab women living in Israel. The sample included 268 participants: $\mathbf{1 1 4}$ Jewish women and 154 Arab women. For both ethnic groups, satisfaction with life was negatively correlated with emotional cutoff. Among Arab women, satisfaction with life was found positively associated with I-position, marriage duration and education. The examination of crosscultural differences yielded several findings: Arab women reported higher levels of emotional reactivity and I-position than Jewish women. No cultural differences were found in the levels of fusion with others, emotional cutoff and satisfaction with life. The current findings show that working women, who are highly differentiated, are satisfied with life to a greater extent than non-working women who are poorly differentiated. In general, the research findings provide support to the universality of the Family Systems Theory, and to the argument that differentiation of self is an important factor which may influence emotional wellbeing in all cultures.
\end{abstract}

Keywords: Differentiation of Self; Emotional Reactivity; I-Position; Emotional Cutoff; Fusion with Others; Satisfaction with Life

\section{INTRODUCTION}

Differentiation of self has become one of the key concepts of Bowen's theory [1]. Bowen argued that differentiation of self plays an important role in the individual's optimal functioning and well being and that it is univer- sal, and accordant to all cultures [2]. The literature supports this argument. In a series of studies differentiation of self was found positively associated with well being [3] and satisfaction (e.g., marital satisfaction) [4], and negatively associated with anxiety [e.g., 5-8] and stress [9] in both individualistic and collectivist societies [10]). Yet, it should be noted that due to cross-cultural differences that were found with respect to the dimensions of differentiation of self, it was suggested that The DSI-R might operate differently in Eastern and Western societies. To the best of our knowledge, no cross-cultural research has examined the relationship between differentiation of self and satisfaction with life amongst participants from collectivist and individualistic societies, living at the same country.

\subsection{Differentiation of Self and Satisfaction with Life}

According to Bowen's theory, at least four factors are indicators of a person's levels of differentiation of self: emotional reactivity, emotional cutoff, fusion with others and the ability to take an I-position [8,11]. Emotional reactivity, describes a person's tendency to react to stress by irrational emotional flooding; fusion with others taps the inclination to create complex and dependent relationships with significant others; emotional cutoff, reflects one's tendency to end inter-personal relationships and cut them off as a way of dealing with tension and conflicts in symbiotic relationships; "I" position taps the individual's ability to stand up for himself and independently and autonomously express his/her will.

Poorly differentiated people tend to react with a high amount of emotional flooding, focusing their attention more on the emotional episode than on fulfilling tasks. They are likely to create fused relationships, react to stressful events by fusion or emotional cutoff, and expe- 
rience unstable emotions and mood swings, finding it hard to keep themselves on track for the benefit of certain goals or their own benefit in a reasonable and rational manner [12]. On the other hand, highly differentiated people are able to adopt a position in inter-personal relationships, adjust their feelings, as well as retain their personal identity within substantial and intimate relationships, think, feel and act for themselves [3]. They are able to distinguish between emotional and rational processes and react efficiently and adaptively to stressful conditions $[2,8,11,13]$.

In a series of studies negative links were found between differentiation of self and various anxieties, such as, trait anxiety [8], separation anxiety [5,6,12], social anxiety [7], psychiatric symptoms, depression symptoms $[3,14,15]$ physiological symptoms [10,16], stress [17], and over involved counter-transference behaviors [18]. In addition, positive associations were found between differentiation of self and psychological adaptation, the ability to solve social problems [19], mental wellbeing and psychological health $[3,14,20]$, marital satisfaction [4], and life satisfaction $[21,22]$.

Satisfaction with life, reflects a sense of contentment and feelings of congruency between wants or needs and accomplishments or resources, and can be taken as a measure of quality of life [23-25]. It is one of the basics of mental wellbeing that may affect the individual on several planes of life. It may influence rational and intellectual functioning, as well as physical and mental health [26,27].

Research examining participants from Western societies has corroborated Bowen's [2] assertion that highly differentiated individuals are more satisfied with their life [28] and marital relations [6]. This association was found to be different between the sexes. Amongst men marital satisfaction was found negatively correlated with emotional reactivity and emotional cutoff, while amongst women marital satisfaction was found negatively associated with emotional cutoff only [4].

\subsection{Differentiation of Self and Satisfaction with Life: Cross Cultural Research}

Only a few studies have examined the relations between differentiation of self and satisfaction within diverse ethnic cultural groups, yielding mixed results. One of the first studies conducted among Filipinos participants, was aimed at examining the assumption that differentiation of self would have a different meaning in the Filippine collectivist context relative to an American individualistic context. Specifically, it was hypothesized that a high level of fusion with others would be associated with low symptomatology and that standing up for one's beliefs (I-positions) would be harder to maintain due to strong allegiance to the family and community [3]. The
Filippine participants reported higher levels of "I" position, and emotional cutoff, and lower levels of emotional reactivity than their American counterparts. No cultural differences were found in regard to fusion with others.

In another research examining differentiation of self, Chung and Gale [29] stated that the need for autonomy and the sense of belonging were shared throughout all societies, but the value of differentiation of self and autonomy was emphasized in individualistic societies, while the values of belonging and closeness were perceived more important in collectivistic societies. In addition, Tamura \& Lau's study [30] showed that the Japanese tended to over-emphasize fusion with others, and lessen the importance of the separation process, whereas the British participants reported lower levels of fusion with others. In a study which examined differentiation of self among European-American students and Korean students, the Koreans reported lower levels of differentiation of self and "I" position, and higher levels of emotional reactivity, emotional cutoff and fusion with others, in comparison to their European-American counterparts [29]. In a recent research study, Chung \& Gale [31] found that American families were encouraging their members to develop a high level of differentiation of self than Korean families. It was also found that family functioning was positively associated with differentiation of self. Most of the dimensions of family functioning were negatively associated with emotional reactivity and emotional cutoff, and positively associated with "I" position within both ethnic groups. These contacts were weak among the Korean participants.

In a study conducted among Druze mothers in Israel [12], no differences were found in the levels of differentiation of self between Jewish and Druze participants. Yet, Druze mothers reported higher levels of fusion with others and "I" position than their Jewish counterparts. Another recent study conducted among Israeli students, showed that Arab students reported higher levels of "I" position and emotional cutoff, and lower levels of fusion with others and emotional reactivity than Jewish students [10].

Only a few studies examined cross-cultural differences in satisfaction with life. Thus, for example, it was found that Asians put greater importance on the individual's level of satisfaction with life than did Europeans [25]. In other studies participants from collectivist societies reported a lower level of satisfaction with life than participants from individualistic societies [32]. It was argued that among people from Western societies, satisfaction with life was impacted by health and professional status, whereas among people from Eastern societies satisfaction with life was impacted mostly by social relationships [33]. In a study carried out in Israel comparing Jewish and Arab women [26], Jewish women reported a 
higher level of satisfaction with life. Among Arab women, satisfaction with life was positively associated with education and spouses' support.

\subsection{Jewish and Arab Women in Israel}

The current study was conducted among Jewish and Arab women in Israel. The Jewish women belong to Western individualistic culture, whereas the Arab women belong to a minority group and a society defined as Eastern and collectivistic [34,35]. The Arabs, citizens of the State of Israel, comprise $20.5 \%$ of the total Israeli population (the majority are Moslems) [36], and are defined as a group, which differs from the Jewish majority by language, religion, culture, historic narrative, geographical areas and education system [35].

The Arab society is in the midst of a change from a collectivistic to an individualistic society. The transition can be observed in many areas, such as the individual's and women's status, education, and the transition to a limited, nuclear family [34,37]. At the same time the Arab population has to adhere to social and familial norms and values [37]. This is a stage of transition between tradition and modernity, where an attempt is made to mimic Western culture's norms, without actually incorporating them. On the one hand, this process has weakened the collectivist familial life as well as the traditional culture's values, but on the other hand it has not led to the construction of a strong modern identity [38].

Another significant process that is occurring in these societies is the change in the woman's status. Today, more and more women continue learning after high school and develop careers while receiving support from their families. This change has made the women in Asian societies an active factor in workforce, and has also provided them with financial stability and independence. However, still, the Asian societies emphasize the traditional collective values, preserving social ties, honor and devotion to their parents, and commitment to social values and norms, such as the woman's concern for the home and the children, while retaining the husband's role as the head of the family [29,39].

\subsection{Summary, Questions and Hypotheses}

The review of the literature reveals that the few studies that have examined cross cultural differences in the levels of differentiation of self and satisfaction with life, yielded mixed results. Specifically, participants from collectivists societies reported higher levels of fusion with others [12,29] and emotional cutoff [3,10,29]. There are no consistent findings regarding I-position and emotional reactivity. For example, several researchers found higher levels of I-position $[10,12]$ and emotional reactivity [29] among participants from collectivist societies. In contrast, other researchers found lower levels of I-position [29] and emotional reactivity [3] among participants from collectivist societies. In several studies participants from collectivist societies reported a lower level of satisfaction with life than participants from individualistic societies [26,32].

To date, no research has examined these differences between two main ethnic groups living in the same country. Specifically, no research has examined the differences between Jews and Arabs living in Israel in this regard. Therefore, the first aim of the present study was to assess the differences between Jewish and Arab women in the levels of differentiation of self and satisfaction with life. The second aim is to assess the relationships between differentiation of self and satisfaction with life.

The following hypotheses were thereby tested:

1) Arab women will report higher levels of I-position, emotional reactivity, fusion with others and emotional cutoff than their Jewish counterparts.

2) Jewish women will report a higher level of satisfaction with life than their Arab counterparts.

3) Differentiation of self (emotional reactivity, I-position, emotional cutoff, fusion with others) will be positively associated with satisfaction with life among both ethnic groups:

Satisfaction with life will be positively correlated with I-position, and inversely correlated with emotional reactivity, emotional cutoff and fusion

\section{METHOD}

\subsection{Participants}

A volunteer sample of women was recruited to take part in the research project. Prospective participants were Arab and Jewish women from northern Israel. In order to recruit Arab women, we chose two elementary schools and two community centers in a northern Israeli city, and two high schools in the "Triangle" as well. All the teachers and guides were asked to participate. In order to recruit Jewish women three schools and two community centers were chosen in a northern city in Israel, and all teachers and guides were asked to participate in the study. Of 160 Jewish women, 125 returned the questionnaires. Only, 114 were acceptable. Of 160 Arab women, 158 returned the questionnaires. Only 154 were acceptable. The women who were excluded did not complete part of the questionnaires. The final sample consisted of 154 Arab Moslem Women between the ages of 30 - 60 (The mean age was $42.26, \mathrm{SD}=7.93)$, and 114 Jewish women, between the ages of 30 - 60 (The mean age was 46.39 , $\mathrm{SD}=8.14$ ) (see Table 1). The study's sample size was determined by definition of power for regression with 7 variables, while the effect size factor $=0.15, \alpha=0.05$, power $=0.90$. The sample size was at least 108 partici- 
Table 1. Demographic variables of the sample.

\begin{tabular}{ccccccc}
\hline & $\begin{array}{c}\text { Arab women } \\
(\mathbf{n}=\mathbf{1 5 4})\end{array}$ & \multicolumn{2}{c}{$\begin{array}{c}\text { Jewish women } \\
(\mathbf{n}=\mathbf{1 1 4})\end{array}$} & \multicolumn{2}{c}{$\begin{array}{c}\text { Total } \\
(\mathbf{N}=\mathbf{2 6 8})\end{array}$} \\
\hline & $\mathrm{N}$ & $\%$ & $\mathrm{~N}$ & $\%$ & $\mathrm{~N}$ & $\%$ \\
\hline Education level & & & & & & \\
High school & 77 & 50.00 & 53 & 46.50 & 130 & 48.50 \\
B.A & 61 & 39.60 & 38 & 33.30 & 99 & 36.90 \\
M.A & 15 & 9.70 & 18 & 15.80 & 33 & 12.30 \\
Ph.D. & 0 & 0 & 5 & 1.90 & 5 & 1.90 \\
$\begin{array}{c}\text { Employment } \\
\text { status }\end{array}$ & & & & & & \\
employed & 99 & 64.30 & 74 & 64.90 & 173 & 64.60 \\
women & & & & & & \\
unemployed & 55 & 35.70 & 40 & 35.10 & 95 & 35.40 \\
women & & & & & & \\
Marital status & & & & & & \\
marred & 110 & 71.40 & 76 & 66.70 & 186 & 69.40 \\
single & 37 & 24 & 23 & 20.20 & 60 & 22.40 \\
divorced & 6 & 3.90 & 12 & 10.50 & 18 & 6.70 \\
Widow & 1 & 0.60 & 3 & 2.60 & 4 & 1.50 \\
Residence place & & & & & & \\
village & 52 & 33.80 & 8 & 7 & 60 & 22.40 \\
city & 102 & 66.20 & 81 & 74.10 & 183 & 68.30 \\
moshav & 0 & 0 & 16 & 14 & 16 & 6 \\
kibbutz & 0 & 0 & 9 & 7.90 & 9 & 3.40 \\
\hline & & & & & &
\end{tabular}

pants for each group. All participants in the study met our inclusion criterion of being in an intact family with two biological parents living in the home.

\subsection{Measures}

\subsubsection{Satisfaction with Life Index A (LSIA)}

The Satisfaction with life Index A is a 20-item self report measure designed for use with adults [40]. The inventory was translated and adapted into Hebrew [41], and into Arabic for the purpose of the present study, using Brislin's back-translation method for cultural research [42]. First, a neutral mother-tongue quality Arabic-English speaker translated it from English to Arabic. Afterwards, it was translated back from Arabic into English by another neutral mother-tongue quality ArabicEnglish speaker. The inventory was piloted on 20 Arab women. Items wording was corrected and clarified according to their suggestions.

The questionnaire is composed of 12 items which are positively worded, a sample item is "Today I am content, just like I was when I was young"; and 8 items which are negatively worded. A sample item is "Most of the things I do are boring or monotonous". Each item had three possible answers to choose: "agree", "disagree", and "?" (The "question mark" meant that the phrase was irrelevant for the participant). Participants are asked to record their response on a three-point rating scale, with the an- chors of (2) = "agree" for a positive item, and "disagree" for a negative item, $(0)=$ "agree" for a negative item and "disagree" for a positive item, and (1) = ? For both positive and negative items. The scale item score is calculated from 0 (when participants answered all positive items with "disagree" and all negative items with "agree") to 40 (when participants answered all positive items with "agree" and all negative items with "disagree"). The current study reported acceptable internal consistency reliabilities; Cronbach alphas were $\alpha=0.75$ for the Hebrew version, and $\alpha=0.76$ for the Arabic version.

\subsubsection{The Differentiation of Self Inventory-Revised}

We assessed levels of differentiation of self using the DSI-R [8], translated into Hebrew [4,17] and to Arabic for the purpose of the present study, using Brislin's backtranslation method for cultural research [42]. First, a neutral mother-tongue quality Arabic-English speaker translated it from English to Arabic. Afterwards, it was translated back from Arabic into English by another neutral mother-tongue quality Arabic-English speaker. The inventory was piloted on 20 Arab women. Items wording was corrected and clarified according to their suggestions.

The inventory is a 46-item self-report measure that focuses on adults, their significant relationships, and their current relations with family of origin. It includes four subscales: emotional reactivity (ER), I-position (IP), emotional cutoff (EC), and fusion with others (FO). A sample item is: "People have remarked that I'm overly emotional" (ER). The fusion subscale used in this study was the updated version by Skowron and Schmitt [43], translated to Hebrew using the "back translation" method [4]. Participants respond to items on a six-point Likert-type scale, ranging from 1 (not at all true for me) to 6 (very true for me). DSI-R subscale scores were calculated by averaging the mean scores of the items in each category. The DSI-R range is therefore $1-6$, with higher scores reflecting greater differentiation in IP subscale, and lower scores reflecting greater differentiation in ER, EC and FO subscales. Internal consistency (Cronbach's alpha) in the current study was 0.67 for DSI full-scale, 0.69 for emotional reactivity, 0.63 for I-position, 0.75 for emotional cutoff, and 0.65 for fusion with others. The Arabic translated questionnaire's internal consistency was as follow, 0.82 for DSI full-scale, 0.76 for emotional reactivity, 0.60 for I-position, 0.66 for emotional cutoff, and 0.63 for fusion with others.

\subsubsection{Background Questionnaire}

This questionnaire was constructed specifically for the current study to yield information regarding age, marital 
status, number of children, length of marriage, nationality and religion.

\subsection{Procedure}

The questionnaires were distributed to 160 Jewish female and 160 Arab female, all of them live in the north of Israel. Each participant received a questionnaire and filled it out privately. Of 125 questionnaires returned by Jewish participants, 114 were valid. Of 158 questionnaires returned by Arab participants, 154 were valid. Upon the receipt of the approval of school principals' and the community centers' managers' to conduct the study, as well as the receipt of participants' consent to take part in the research, a meeting was held by two research assistants in each center. The meetings with the working women were set up during their recess or after work. The appointments with non-working women were set at the community centers. The research assistants clarified the aims of the study and promised discretion and anonymity. Each participant received a questionnaire and filled it out privately. The assistants were present while completing the questionnaires to ensure comprehension and answer questions. The time taken to fill out the questionnaires was approximately 20 minutes.

\section{RESULTS}

Means, standard deviations and ranges of all study variables are presented in Table 2.

In order to test the first hypothesis regarding cultural differences in the levels of differentiation of self, and the second hypothesis regarding cultural differences in the levels of satisfaction with life, we opted for a series of independent sample t-tests (see Table 2). As shown in Table 2, significant cultural differences were found showing higher levels of emotional reactivity and I-position among Arab women. No significant differences were found in the levels of fusion with others, emotional cutoff and satisfaction with life, partially supporting Hypotheses 1,2 .

To test the third hypothesis regarding the relationship between differentiation of self and satisfaction with life among Jewish and Arab women, partial correlations were run. As shown in Table 3, satisfaction with life was positively correlated with I-position, and negatively correlated with emotional cutoff among both Jewish and Arab women. Emotional reactivity and fusion with others were negatively correlated with satisfaction with life only among the Arab women. This means that among the Arab women, higher level of satisfaction with life was found among those who reported a higher level of I-position and lower levels of emotional reactivity, emotional cutoff and fusion with others.
Table 2. Means, Standard Deviations, Ranges, and t-Tests Analyses.

\begin{tabular}{|c|c|c|c|c|c|}
\hline \multirow{2}{*}{ Variable } & \multicolumn{2}{|c|}{$\begin{array}{c}\text { Arab women } \\
\mathrm{n}=154\end{array}$} & \multicolumn{2}{|c|}{$\begin{array}{c}\text { Jewish women } \\
\mathrm{n}=114\end{array}$} & \multirow{2}{*}{$\mathrm{t}(266)$} \\
\hline & $\begin{array}{l}\text { Mean } \\
(\mathrm{SD})\end{array}$ & $\begin{array}{l}\text { Min } \\
\text { Max }\end{array}$ & $\begin{array}{c}\text { Mean } \\
(\mathrm{SD})\end{array}$ & $\begin{array}{l}\text { Min } \\
\text { Max }\end{array}$ & \\
\hline \multirow{2}{*}{ ER } & 4.00 & 1.73 & 3.51 & 1.82 & \multirow{2}{*}{$-5.18^{* * *}$} \\
\hline & $(0.89)$ & 5.91 & $(0.68)$ & 4.91 & \\
\hline \multirow{2}{*}{$\mathrm{EC}$} & 3.08 & 1.08 & 3.00 & 1.00 & \multirow{2}{*}{-0.78} \\
\hline & $(0.81)$ & 5.50 & $(0.80)$ & 4.50 & \\
\hline \multirow{2}{*}{ FO } & 3.74 & 1.67 & 3.74 & 2.00 & \multirow{2}{*}{0.01} \\
\hline & $(0.70)$ & 5.33 & $(0.63)$ & 5.33 & \\
\hline \multirow{2}{*}{ IP } & 4.09 & 2.27 & 3.89 & 2.36 & \multirow{2}{*}{$-2.22^{* *}$} \\
\hline & $(0.73)$ & 5.73 & $(0.73)$ & 5.82 & \\
\hline \multirow{2}{*}{ LSIA } & 25.53 & 4.00 & 24.31 & 8.00 & \multirow{2}{*}{-1.33} \\
\hline & (7.41) & 40.00 & (7.39) & 40.00 & \\
\hline
\end{tabular}

${ }^{* *} \mathrm{p}<0.01 ;{ }^{* * *} \mathrm{p}<0.001$. Note: ER = Emotional reactivity; EC = Emotional cutoff; FO = Fusion with others; IP = I-position; LSIA = Satisfaction with life $(\mathrm{N}=268)$.

Table 3. Partial correlations between differentiation of self subscales and satisfaction with life.

\begin{tabular}{ccc}
\hline \multirow{2}{*}{$\begin{array}{c}\text { Differentiation of self } \\
\text { subscales }\end{array}$} & \multicolumn{2}{c}{ Satisfaction with life } \\
\cline { 2 - 3 } & $\begin{array}{c}\text { Arab women } \\
(\mathbf{n}=\mathbf{1 5 4})\end{array}$ & $\begin{array}{c}\text { Jewish women } \\
(\mathbf{n}=\mathbf{1 1 4})\end{array}$ \\
\hline ER & $-0.19^{*}$ & -0.18 \\
EC & $-0.32^{* *}$ & $-0.50^{* *}$ \\
FO & $-0.17^{*}$ & -0.04 \\
IP & $0.29^{* *}$ & $0.33^{* *}$ \\
\hline
\end{tabular}

${ }^{*} \mathrm{p}<0.05 ;{ }^{* *} \mathrm{p}<0.01$. Note: $\mathrm{ER}=$ Emotional reactivity; EC $=$ Emotional cutoff; FO = Fusion with others; IP = I-position; LSIA = Satisfaction with life $(\mathrm{N}=268)$.

The contribution of differentiation of self to the level of satisfaction with life was examined in a series of hierarchical regression analyses (Table 4). Given that cultural differences were found in two subscales (emotional reactivity and I-position), two separate hierarchal regressive analyses were run (for Jewish an Arab women separately). Background scores of marriage duration, number of children, age, education level and employment status ( $1=$ employed, $0=$ unemployed $)$ were entered into the equation regression first. Participants' satisfaction with life served as the dependent variable. In the second step, women levels of emotional reactivity, emotional cutoff, fusion with others and "I" position were entered to examine the contribution of differentiation of self to satisfaction with life (see Table 4).

As shown in Table 4, all regression models were significant. Background variables and differentiation of self accounted for $34 \%$ of the variance in satisfaction with life for the Jewish participants, and $34 \%$ of the variance for the Arab participants. The introduction of DSI-R subscales asses an explained variance of 0.17 for Jewish 
Table 4. Results of multiple hierarchical regression analyses, with women's satisfaction with life as dependent variable and background variables and levels of differentiation of self as independent variables.

\begin{tabular}{|c|c|c|c|c|c|c|}
\hline & \multicolumn{3}{|c|}{$\begin{array}{c}\text { Arab women } \\
(\mathrm{n}=154)\end{array}$} & \multicolumn{3}{|c|}{$\begin{array}{c}\text { Jewish women } \\
(\mathrm{n}=114)\end{array}$} \\
\hline & B & $\mathrm{SE}$ & $\beta$ & B & SE & $\beta$ \\
\hline \multicolumn{7}{|l|}{ Step 1} \\
\hline $\begin{array}{l}\text { Marriage } \\
\text { duration }\end{array}$ & 0.29 & 0.10 & $0.43^{* *}$ & 0.07 & 0.08 & 0.11 \\
\hline Children number & -0.61 & 0.42 & -0.18 & 0.52 & 0.58 & 0.12 \\
\hline Age & -0.08 & 0.09 & -0.09 & -0.04 & 0.09 & -0.04 \\
\hline Education & 2.40 & 1.00 & $0.22^{*}$ & 1.02 & 0.83 & 0.12 \\
\hline \multirow[t]{2}{*}{$\begin{array}{l}\text { Employment } \\
\text { status }\end{array}$} & 3.56 & 1.36 & $0.23^{*}$ & 4.13 & 1.52 & $0.27^{* *}$ \\
\hline & \multicolumn{3}{|c|}{$\mathrm{R}^{2}=0.22^{* * *}$} & \multicolumn{3}{|c|}{$\mathrm{R}^{2}=0.17^{* *}$} \\
\hline \multicolumn{7}{|l|}{ Step 2} \\
\hline $\begin{array}{l}\text { Marriage } \\
\text { duration }\end{array}$ & 0.27 & 0.09 & $0.41^{* *}$ & -0.02 & 0.08 & -0.04 \\
\hline $\begin{array}{l}\text { Children } \\
\text { number }\end{array}$ & -0.73 & 0.40 & -0.21 & 0.77 & 0.54 & 0.18 \\
\hline Age & -0.10 & 0.09 & -0.11 & -0.01 & 0.09 & -0.01 \\
\hline Education & 1.93 & 0.94 & $0.18^{*}$ & 0.67 & 0.77 & 0.08 \\
\hline $\begin{array}{l}\text { Employment } \\
\text { status }\end{array}$ & 2.81 & 1.29 & $0.18^{*}$ & 1.99 & 1.47 & .13 \\
\hline ER & -0.71 & 0.75 & -0.09 & -0.15 & 1.07 & -0.01 \\
\hline $\mathrm{EC}$ & -2.12 & 0.77 & $-0.24^{* *}$ & -3.63 & 0.84 & $-0.40^{* * *}$ \\
\hline FO & 0.80 & 1.03 & 0.08 & 0.49 & 1.17 & 0.04 \\
\hline \multirow[t]{3}{*}{ IP } & 2.70 & 0.69 & $0.27^{* * *}$ & 1.33 & 0.90 & 0.13 \\
\hline & \multicolumn{3}{|c|}{$\Delta \mathrm{R}^{2}=0.12_{* * *}$} & \multicolumn{3}{|c|}{$\Delta \mathrm{R}^{2}=0.17^{* * *}$} \\
\hline & \multicolumn{3}{|c|}{$\begin{array}{c}\mathrm{R}^{2}=0.34, \\
\mathrm{~F}(9,143)=8.27^{* * *}\end{array}$} & \multicolumn{3}{|c|}{$\begin{array}{c}\mathrm{R}^{2}=0.34 \\
\mathrm{~F}(9,143)=5.88^{* * *}\end{array}$} \\
\hline
\end{tabular}

${ }^{*} \mathrm{p}<0.05 ;{ }^{* *} \mathrm{p}<0.01 ;{ }^{* * *} \mathrm{p}<0.001$. Note: $\mathrm{ER}=$ Emotional reactivity; EC $=$ Emotional cutoff; $\mathrm{FO}=$ Fusion with others; $\mathrm{IP}=\mathrm{I}$-position $(\mathrm{N}=268)$.

participants, and 0.12 for Arab participants, creating a total $R^{2}$ of 0.34 . This change in $R^{2}$ was significantly different from the first step. That is, the added contribution of women's differentiation of self explained further variance in women's satisfaction with life scores $(\mathrm{F}(9,103)=$ $5.88, \mathrm{p}<0.001$, among Jewish women and $\mathrm{F}(9,143)=$ 8.27, $\mathrm{p}<0.001$ among Arab women).

Partially supporting hypothesis 3, emotional cutoff was inversely correlated with satisfaction with life within both ethnic cultural groups. Correlations between satisfaction with life on the one hand and emotional reactivity and fusion with others on the other hand did not reach significance. For Arab women, satisfaction with life was positively correlated with I-position, as well as with several background variables. Specifically, satisfaction with life was positively correlated with marriage duration, education and employment, showing that more satisfied Arab women are educated, working and married. Moreover, the longer they are married, the more they are satisfied with their life.

As for Jewish women satisfaction with life was posi- tively correlated with employment. However, when employment was introduced to the regression equation together with differentiation of self it did not reach significance (see Table 4).

To further examine the data, a series of two-tailed, independent sample $t$-tests, each with an alpha of 0.01 , were run to examine differences between working and non-working women in the levels of differentiation of self and satisfaction with life. Among Arab women the $t$-tests yielded significant differences between working and non-working women, showing higher levels of satisfaction with life and lower levels of emotional reactivity and emotional cutoff among employed women. Among Jewish women, significant differences were found, indicating higher levels of satisfaction with life and I-position, and lower levels of emotional cutoff among employed women (Table 5).

\section{DISCUSSION}

The present study sheds light on several notions of Bowen's theory, reinforcing the importance of differentiation of self to well being. It provides partial support for the assumption that differentiation of self is positively related to satisfaction with life among Jewish and Arab women. Yet the findings yielded several cultural differences.

The first hypothesis regarding cultural differences in the level of differentiation of self was partially supported. Arab women reported a higher level of "I" position than their Jewish counterparts, supporting previous research studies pointing to higher levels of "I" position among participants from collectivist societies $[3,10,12]$.

As mentioned previously Arab women in Israel are

Table 5. Independent t-test analyses to examine differences between working and non-working women.

\begin{tabular}{ccccc}
\hline & Variable & $\begin{array}{c}\text { Non-working } \\
\text { women }\end{array}$ & $\begin{array}{c}\text { Working } \\
\text { women }\end{array}$ & T value \\
\hline & & Mean (SD) & Mean $(\mathrm{SD})$ \\
\hline & ER & $4.24(0.87)$ & $3.87(0.88)$ & $\mathrm{t}(152)=2.46^{*}$ \\
$\begin{array}{c}\text { Arab } \\
\text { women }\end{array}$ & EC & $3.33(0.77)$ & $2.94(0.80)$ & $\mathrm{t}(152)=2.86^{*}$ \\
$\mathbf{n = 1 5 4}$ & FO & $3.89(0.74)$ & $3.65(0.67)$ & $\mathrm{t}(152)=1.97$ \\
& IP & $4.05(0.71)$ & $4.11(0.74)$ & $\mathrm{t}(152)=-0.46$ \\
& LSIA & $22.12(7.21)$ & $27.42(6.85)$ & $\mathrm{t}(152)=-4.50^{* * *}$ \\
& ER & $3.58(0.59)$ & $3.47(0.72)$ & $\mathrm{t}(112)=0.85$ \\
$\begin{array}{c}\text { Jewish } \\
\text { women }\end{array}$ & EC & $3.34(0.57)$ & $2.82(0.85)$ & $\mathrm{t}(112)=3.90^{* * *}$ \\
$\mathbf{n = 1 1 4}$ & FO & $3.67(0.60)$ & $3.77(0.65)$ & $\mathrm{t}(112)=-0.80$ \\
& IP & $3.58(0.65)$ & $4.05(0.72)$ & $\mathrm{t}(112)=-3.47^{* *}$ \\
& LSIA & $20.57(5.47)$ & $26.33(7.53)$ & $\mathrm{t}(112)=-4.68^{* * *}$ \\
\hline
\end{tabular}

${ }^{*} \mathrm{p}<0.05 ;{ }^{* *} \mathrm{p}<0.01 ;{ }^{* * *} \mathrm{p}<0.001$. Note: ER = Emotional reactivity; EC $=$ Emotional cutoff; FO = Fusion with others; IP = I-position; LSIA = Satisfaction with life $(\mathrm{N}=268)$. 
undergoing a period of change which is reflected in their status, education, and transition to a limited, nuclear family [34,37]. At the same time they have to adhere to social and familial norms and values [37]. It is possible that in order to improve their status, to struggle for equality and to develop their ego and identity, they have to demonstrate determination, to stand up for themselves, and to fight for their rights more forcefully and assertively [44]. It should be noted that Israeli Arab women are part of a minority, and therefore are likely to invest more efforts in improving their own as well as their offspring's education and standard of living [45].

Arab women reported higher levels of emotional reactivity than their Jewish counterparts. This finding is consistent with Chung and Gale's [29] findings showing higher levels of emotional reactivity among Korean students than among European-American students. However it refutes other studies' results indicating lower levels of emotional reactivity among participants from collectivist societies $[3,10]$.

The reason for this result may lie in the Arab tradition, according to which women, even if they develop a professional career, are still the sole caretakers at home [46]. It was suggested that though the Arab society in Israel has adopted modern individualistic society values concerning women's status, education and career-development. The Arab woman is still required to follow social norms, to live up to social expectations in regard to home tasks [38], and to give up their desires. She is not encouraged to fulfill her own expectations and to make a career [47]. This day-to-day duty of caring for family members, and at the same time developing a career, may increase Arab women's levels of stress and anxiety, and thus, boost emotional reactivity.

Another possible reason is based upon Haj Yahia's [48] assertion that despite the rise in the number of people who need psychological help, the Arab society in Israel still tends to perceive emotional and familial problems as a "failure" or a "sin", resulting in only a small number of people who actually go to therapy and are assisted by therapists. It is likely that the illegitimacy and inability to get help does not allow to reduce emotional reactivity.

Interestingly no cultural differences were found in the levels of fusion with others, refuting previous findings $[10,26,31]$. As mentioned previously, the Arab society is extremely exposed to the Jewish society in Israel, and therefore is undergoing a process of modernization. It is likely that the exposure to Western norms and lifestyle has led to changes in personal and familial customs and behaviors. Thus, for example, many young women work outside the home, study at colleges or universities, and therefore are less involved in the life of the extended family [34].

No cultural differences were found in the levels of emotional cutoff, corroborating Peleg et al.'s [12] findings. An explanation suggested by Sharabi [38] is that the encounters with Jewish women help Arab women to express their wishes and desires, and to have direct dialogues, instead of disconnecting and cutting off.

The regression analyses yielded for both ethnic groups negative correlations between emotional cutoff and satisfaction with life. For Arab women positive correlations were found between I-position and satisfaction with life, partially confirming hypothesis 3 . These findings support previous studies, showing positive connections between differentiation of self on the one hand, and emotional wellbeing [20], satisfaction with life [21,22], and marital satisfaction [4] on the other hand.

A possible explanation for the association between satisfaction with life and I-position among Arab women relies on Bowen's theoretical approach [11], according to which a high level of differentiation of self allows higher levels of psychological adaptation, emotional wellbeing, physical and mental health. This is due to the fact that a well-differentiated person is better able to guard his intimacy and autonomy, function more efficiently, while taking a stand in inter-personal relationships, showing proficiency in problem-solving and focusing on goals important to him/her. Possibly, all this might allow women to feel stronger and more substantial. Also it might help them to struggle for their self fulfillment and self appreciation as well as to create the basis for agreeable and satisfactory familial and intimate relations [24,25].

As for the connection between emotional cutoff and satisfaction with life, it is likely that a vicious circle emerges: women with high levels of emotional cutoff find it difficult to regulate their emotions when they experience intimate relationships. Given that they feel higher levels of tension and anxiety, they emotionally distance themselves in order to cope with feelings of anxiety. Paradoxically, distance from others may in turn increase feelings of loneliness and anxiety [14,49,50,51], thus decreasing their satisfaction with life.

Interestingly, a significant effect was found for marriage duration among Arab women, showing that the longer they were married, the higher their level of satisfaction with life. This finding contradicts previous research conducted among women from individualistic societies $[4,52]$. It is likely that women from collectivist societies tend to define themselves by their marriage, and believe in marriage as a source of support and self satisfaction [53]. Jewish women, conversely, belong to an individualistic society which emphasizes achieving satisfaction and self-fulfillment not only by means of marriage, but also by career-development [46], hobbies and social contacts. This issue merits further investigation.

The analyses yielded another interesting effect pointing to higher levels of satisfaction with life among work- 
ing women (Jewish and Arab) than among non working women. This finding is consistent with previous studies pointing to positive correlations between satisfaction with life on the one hand and employment [52,54], and education [26] on the other hand. A possible explanation for this may be related to the accession of Arab women to the labor market, as well as to the improvement in the working women's economic situation which allows a higher standard of living, which in turn may lead to a higher level of satisfaction $[25,55]$. In addition to economic welfare, being employed plays a big role in feeling worthwhile, providing a feeling of self-fulfillment, self pride and self confidence [56]. In contrast, women who stay at home most of their time may feel less appreciated, bored and moody $[52,56]$.

In regard to differentiation of self, working women (Arab and Jewish) reported a lower level of emotional cutoff than non-working women, partially confirming Kulick and Ryan's [26] findings. In addition, Jewish working women reported higher levels of "I" position than non-working women. It should be noted that for Arabs, working women reported higher level of I-position too, but the result did not reach significance. It is suggested that Working women are likely to deal a lot with issues related to their working conditions, [45], trying to achieve equal rights and to advance their career [56] (e.g., asking for assistance and raise, tight schedule, and superiors' criticism). All these tasks require verbal confrontation and may lead to a greater ability to manage direct dialogues instead of disengaging and disconnecting.

Arab working women reported a lower level of emotional reactivity than non-working women. This finding supports previous studies [12], showing that women who performed many tasks (running a household and holding a job) reported a lower level of anxiety concerning leaving the children at home than women who performed only their traditional tasks. It was suggested that mothers who preferred to be employed and liked their job were less anxious about employment-related separations [12]. These women hold more liberal views on mothering and working and have husbands with similar views.

Another possible explanation is that the rapid modernization that the Arab population in Israel is going through, which portrays an increase in working women as one of its expressions. Society may be lowering its expectations from working women, and excusing them for not fully living up to the household-family task-expectations. This attitude may reduce pressure and anxiety levels among working women, whereas non-working women, who are exposed to society's severe criticism in case they do not function as perfect caregivers.

It is valuable to note limitations of the present study as well as some future directions for research. First the pre- sent study relies solely upon the use of self-reports measures. Although self-report measures of internalizing symptoms appear to be less problematic [57], sole reliance on self reports measures allows for confounding of shared method variance. Thus, it would be useful for future research to include the reports of others (e.g., spouses, offspring), which could allow for multiple informant comparisons [58]. Second, due to technical problems, our sample cluster was biased and therefore not systematic. Therefore the findings may not be generalized to more diverse ethnic populations. Sample size may have also affected our results, such that power to detect study differences may have been limited. Thus, this issue merits further investigation with greater sample sized, male participants and additional cultural groups. Third, it is possible that there are additional variables influencing the research findings. Thus, for instance, it would be worthwhile to explore degrees of support women get from their husbands and families in general, and with regard to their work specifically. In a collectivist culture, it is also important to look at community and family pressures leading to social desirability, as well as the women's traditional and modern roles. Fourth, the internal consistency of differentiation of self sub-scales was not high, mainly in the Arabic version. Comparison of DSI-R scores in samples from different cultures may raise a problem, since mean scores for the entire population may differ from one culture to another. Thus, for example, in Skowron's and Friedlander's study of the US [8], the mean scores of DSI sub-scales are different than those in [3]. Cross-validation of these findings in participants of Arab and other Eastern and Western groups is needed to determine whether differentiation of self operates in similar ways across different cultural groups. Specifically, it is suggested to average the mean scores of a series of studies in each culture. Finally, the sample included two main groups: The Arab women represent the collectivist society and the Jewish group represents the individualistic society. It should be noted that the variability in each group may be high, since there are many Jewish families characterized by collectivist patterns, and Arab families who live in big cities and mange modern and individualistic lifestyle. Therefore it is recommended to further research this issue in future research.

\section{CONCLUSIONS}

These limitations notwithstanding, the current research is one of the few studies investigating Bowen theory between two cultural groups. On the whole, the current findings add to the extant literature demonstrating that differentiation of self is an important factor which may influence emotional wellbeing in all cultures, thus providing validity to Bowen's [11] intergenerational theory as well as to its universality. It is important that scientists 
should further research this issue to better understand the role that differentiation of self plays in the lives of people in general, and in collectivist cultures specifically.

In addition, this research offers new insights into the association between differentiation of self and satisfaction with life among Arab and Jewish women, as well as among working and non-working women. Specifically, it is suggested that emotional cutoff is the main variable that may harm satisfaction with life, and that the use of Iposition is very important among Arab women. Methodologically, two questionnaires were translated and adapted into Arabic, thus, enabling research to be conducted among Arab participants.

Importantly, a number of clinical implications can be derived from the findings of this study. It is suggested that highly differentiated women are more satisfied with life. Therefore, it is strongly recommended that when women experience dissatisfaction, the treatment should be focused on improving their level of differentiation of self.

Other important issues that should be addressed in the therapy are marriage duration, education and work, especially among Arab women. Future research is needed to clarify the associations among differentiation of self, marriage duration and culture. Finally, the current research findings provide food for thought in terms of the practical ways in which different ethnic group may be assisted. One matter is the importance of not making a sweeping recommendation but rather directing the specific issues related to differentiation of self to a specific target audience.

\section{ACKNOWLEDGEMENTS}

The authors which to thank Helene Hogri for her valuable help in editing the paper, to Edna Guttman for the statistical assistance, and to Rana Bshara for helping in collecting the data.

\section{REFERENCES}

[1] Bartle-Haring, S., Silverthorn, B., Toviessi, P. and Bhopal, K. (2009) Identity, empathy and "otherness": Asian women, education and dowries in the UK. Race Ethnicity and Education, 12, 27-39. doi:10.1080/13613320802650923

[2] Bowen, M. (1978) Family therapy in clinical practice. Aronson, New York.

[3] Tuason, M.T. and Friedlander, M.L. (2000) Do parents' differentiation levels predict those of their adult children? And other test of Bowen theory in a Philippine sample. Journal of Counseling Psychology, 47, 27-35. doi:10.1037/0022-0167.47.1.27

[4] Peleg, O. (2008) The relation between differentiation of self and marital satisfaction: What can be learned from married people over the course of life? The American Journal of Family Therapy, 36, 388-401.

\section{doi: $10.1080 / 01926180701804634$}

[5] Nikbakht, A., Ahmadi, B.M. and Dashti-Nejad, S.B. (2012) Comparison of self-differentiation amount between two groups of anxious and Non-Anxious People in Bandar Abbas. Journal of Life Science and Biomedicine, 2, 142-146.

http://www.jlsb.science-line.com/attachments/article/16/J LSB-\%202012-\%20B29,\%20142-146.pdf

[6] Peleg, O. and Yitzhak, M. (2011) Differentiation of self and separation anxiety: Is there a similarity between spouses? Contemporary Family Therapy, 33, 25-36. doi:10.1007/s10591-010-9137-Z

[7] Peleg, O. (2005) The relation between differentiation and social anxiety: What can be learned from students and their parents? American Journal of Family Therapy, 33, 167-183. doi:10.1080/01926180590921403

[8] Skowron, E.A. and Friedlander, M.L. (1998) The differentiation of self inventory: Development and initial validation. Journal of Counseling Psychology, 45, 235-246. doi:10.1037/0022-0167.45.3.235

[9] Peleg, O. (2013) The relationship between stressful life events and family patterns. International Journal of Psychology.

[10] Peleg, O. and Rahal, A. (2012) Physiological symptoms and differentiation of self: A cross-cultural examination. International Journal of Intercultural Relations, 36, 719727. doi:10.1016/j.ijintrel.2012.04.001

[11] Kerr, M.E. and Bowen, M. (1988) Family evaluation. Norton, New York.

[12] Peleg, O., Halaby, E. and Whaby, E. (2006) The relationship of maternal separation anxiety and differentiation of self to children's separation anxiety and adjustment to kindergarten: A study in Druze families. Journal of Anxiety Disorders, 20, 973-995. doi:10.1016/j.janxdis.2006.01.008

[13] Gushue, G.V. and Constantin, M.G. (2003) Examining individualism, collectivism, and self-differentiation in African-American college women. Journal of Mental Health Counseling, 25, 1-15.

http://psycnet.apa.org.ezproxy.yvc.ac.il:2048/index.cfm?f $\mathrm{a}=$ search.displayRecord\&id=E207851E-FAF9-9D94-1BB C-E8E4B2D75762\&resultID $=1$ \&page $=1 \& \mathrm{dbTab}=\mathrm{all}$

[14] Jankowski, P.J. and Hooper, L.M. (2012) Differentiation of self: A validation study of the Bowen theory construct. Couple and Family Psychology: Research and Practice, 1, 226-243. doi:10.1037/a0027469

[15] Murdock, N.L., Gore Jr. and Paul, A. (2004) Stress, coping, differentiation of self: A test of Bowen theory. Contemporary Family Therapy, 26, 319-335. doi:10.1023/B:COFT.0000037918.53929.18

[16] Peleg-Popko, O. (2002) Bowen theory: A study of differentiation of self, anxiety and physical symptoms. Contemporary Family Therapy, 24, 355-369. doi:10.1023/A:1015355509866

[17] Bartle-Haring, S. and Lal, A. (2010) Using Bowen Theory to examine Progress in Couple Therapy. The Family Journal, 18, 106-115.

http://tfj.sagepub.com/content/18/2/106.short 


\section{doi:10.1177/1066480710364479}

[18] Connery, A. (2012) The roles of differentiation of self, anxiety and emotional self awareness on destructive countertransference reactions. Doctoral Dissertation, University of Missouri, Kansas City.

[19] Skowron, E.A. (2004) Differentiation of self, personal adjustment, problem solving, and ethnic group belonging among persons of color. Journal of Counseling and Development, 82, 447-456. doi:10.1002/j.1556-6678.2004.tb00333.x

[20] Skowron, E.A., Stanley, K.L. and Shapiro, M.D. (2009) A longitudinal perspective on differentiation of self, interpersonal and psychological well-being in young adulthood. Contemporary Family Therapy: An International Journal, 31, 3-18. doi:10.1007/s10591-008-9075-1

[21] Oishi, S. (2006) The concept of life satisfaction across cultures: An IRT analysis. Journal of Research in Personality, 40, 411-423. doi:10.1016/j.jrp.2005.02.002

[22] Diener, E. (2000) Subjective well-being: The science of happiness and a proposal for a national index. The American Psychologist, 55, 34-43. doi:10.1037/0003-066X.55.1.34

[23] Huebner, E.S. (2004) Research on assessment of life satisfaction of children and adolescents. Social Indicators Research, 66, 3-33. doi:10.1023/B:SOCI.0000007497.57754.e3

[24] Hawkins, M.T., Letcher, P., Sanson, A., Smar, D. and Toumbourou, J.W. (2009) Positive development in emerging adulthood. Australian Journal of Psychology, 61, 89-99. http://link.springer.com/article/10.1023/B:SOCI.0000007 497.57754.e3\#page-1

[25] Wolfgang, J. (2010) Economic, social, and cultural determinants of life satisfaction: Are there differences between Asia and Europe? Social Indicators Research, 97, 85-104. doi:10.1007/s11205-009-9555-1

[26] Kulick, L. and Ryan, P. (2005) Partner relationships, strategies for coping with conflict House-Work and wellbeing: A comparative analysis between Jewish and Arab women. Trends, 43, 633-658.

[27] Lim, M.G. and Jennings, G. (1996) Marital satisfaction of healthy differentiated and undifferentiated couples. The Family Journal, 4, 308-315. doi:10.1177/1066480796044004

[28] Manzi, C., Vignoles, V.L., Regalia, C. and Scabini, E. (2006) Cohesion \& enmeshment revisited: Differentiation, identity and well being in tow European cultures. Journal of Marriage \& Family, 68, 673-689.

http://onlinelibrary.wiley.com/doi/10.1111/j.1741-3737.20 $06.00282 . \mathrm{x} /$ abstract?deniedAccessCustomisedMessage $=$

\&userIsAuthenticated $=$ false doi:10.1111/j.1741-3737.2006.00282.x

[29] Chung, H. and Gale, J. (2006) Comparing self-differentiation and psychological well-being between Korean and European American students. Contemporary Family Therapy, 28, 367-381. doi:10.1007/s10591-006-9013-Z

[30] Tamura, T. and Lau, A. (1992) Connectedness versus separateness: Applicability of family therapy to Japanese families. Family Process, 31, 319-340. doi:10.1111/j.1545-5300.1992.00319.x
[31] Chung, H. and Gale, J. (2009) Family functioning and self-differentiation: A cross-cultural examination. Contemporary Family Therapy, 31, 19-33. doi:10.1007/s10591-008-9080-4

[32] Lee, S.J. and Wu, C.H. (2008) Comparing the level of positive tendency in a life satisfaction evaluation between Chinese and western people. Social Indicators Research, 89, 147-153. doi:10.1007/s11205-007-9227-y

[33] Lou, V. (2010) Life satisfaction of older adults in Hong Kong: The role of social support from grandchildren. Social Indicators Research, 95, 377-391. doi:10.1007/s11205-009-9526-6

[34] Abu Asba, K. (2007) Arab education in Israel: Dilemmas of a national minority. Florsheimer Institute, Jerusalem.

[35] Zidani, S. (2005) Oppression of the Palestinian Arabs in Israel. In: Reiter, Y., Ed., Dilemmas Jewish-Arab relations in Israel, Schocken, Jerusalem, 89-96.

[36] Central Bureau of Statistics (2012). http://www.cbs.gov.il/reader/?MIval=cw_usr_view_SHT ML\&ID $=629$

[37] Kaufman, A., Abu Bakr, Ch. and Saar, E. (2012) Arab society in Israel: Social Mosaic: Eda, family, gender (Volume 2). The Open University, Raanana.

[38] Sharabi, H. (1988) Neopatriarchy: A theory of distorted change in Arab society. Oxford University Press, Oxford.

[39] Khalaila, R. (2008) Modernization and children dedication to elderly parents in Arab-Israeli society. Doctoral Dissertation, The Hebrew University, Jerusalem.

[40] Neugarten, B.L., Havighurst, R.J. and Tobin, S.S. (1961) The measurement of life satisfaction. Journal of Gerontology, 16, 134-143. doi:10.1093/geronj/16.2.134

[41] Shmotkin, D. (1991) The structure of the life satisfaction (index A) in elderly Israeli adults. International Journal of Aging and Human Development, 33, 131-150. doi:10.1093/geronj/16.2.134

[42] Brislin, R.W. (1980) Translation and content analysis of oral and written material. In: Triandis, H.C. and Berry, J. W., Eds., Handbook of cross-cultural psychology: Methodology, Allyn and Bacon, Boston, 389-444.

[43] Skowron, A.E. and Schmitt, A.T. (2003) Assessing interpersonal fusion: Reliability and validity of a new DSI fusion with others subscale. Journal of Marital and Family Therapy, 29, 209-222. doi:10.1111/j.1752-0606.2003.tb01201.x

[44] Weiner-Levy, N. (2006) The flagbearers: Israeli druze women challenge traditional gender roles. Anthropology and Education Quarterly, 37, 217-235. doi:10.1525/aeq.2006.37.3.217

[45] Al-Haj, M. (2005) Education, social change, and control: The case of the Palestinian in Israel. In: Al-Haj, M., Ed., Social critique and commitment, University Press of America, Lanham, 93-106.

[46] Dwairy, M. and Achoui, M. (2010) Parental control: A second cross-cultural research on parenting and psychological adjustment of children. Journal of Child and Family Studies, 19, 16-22. 


$$
\text { doi:10.1007/s10826-009-9334-2 }
$$

[47] Bolus, S. (2003) Integration of Arab women in the Israeli labor market. Association for Civil Rights in Israel, Tel Aviv.

http://www.google.co.il/url?sa=t\&rct=j\&q=\&esrc=s\&frm $=1 \&$ source $=$ web \&cd $=3 \&$ ved $=0$ CDsQFjAC\&url $=$ http $\% 3$ A $\% 2 \mathrm{~F} \% 2 \mathrm{Fwww}$. knesset.gov.il $\% 2 \mathrm{Fcommittees} \% 2 \mathrm{Fheb} \%$ 2Fmaterial\%2Fdata\%2FH07-12-2006 14-32-41 c.doc\&e $\mathrm{i}=$ OtO7UKDdHpDEswb-9YHIBA\&usg=AFQjCNF9K7i LQ8xubIRM7URbicWVzx1whw\&sig2=1lh5DNscbkn-M NTMV1_vBQ

[48] Haj-Yahia, M. (1995) Toward culturally sensitive intervention with Arab families in Israel. Contemporary Family Therapy, 17, 429-447. doi:10.1007/BF02249355

[49] Jagodzinski, W. (2010) Economic, social, and cultural determinants of life satisfaction: Are there differences between Asia and Europe. Social Indicators Research, 97, 85-104. doi:10.1007/s11205-009-9555-1

[50] Borzumato-Gainey, C., Kennedy, A., McCabe, B. and Degges-White, S. (2009) Life satisfaction, self-esteem, and subjective age in women across the life span. Adultspan Journal, 8, 29-42. doi:10.1002/j.2161-0029.2009.tb00055.x

[51] Degges-White, S. and Myers, J. (2006) Women at midlife: An exploration of chronological age, subjective age, wellness, and life satisfaction. Adultspan Journal, 5, 6780. doi:10.1002/j.2161-0029.2006.tb00018.x

[52] Zussman, N. and Romanov, D. (2004) Happiness of na- tions: Israelis' satisfaction with their lives. Bank of Israel Survey, Jerusalem.

[53] Ng, K.M., Loy, J., Gudmunson, C. and Cheong, W.N. (2009) Gender differences in marital and life satisfaction among Chinese Malaysians. Sex Roles, 60, 33-43. doi:10.1007/s11199-008-9503-6

[54] Antaramian, S.P., Huebner, E.S. and Valois, R.F. (2008) Adolescent life satisfaction. Applied Psychology: An International Review, 57, 112-126. doi:10.1111/j.1464-0597.2008.00357.x

[55] Melin, R., Fugl-Meyer, K.S. and Fugl Meyer, A.R. (2003) Life satisfaction in 18- to 64-year-old Swedes: In relation to education, employment situation, health and physical activity. Journal of Rehabilitation Medicine, 35, 84-90. doi:10.1080/16501970306119

[56] Olrate, S.W. (2000) The female professional: Parenting, career, choices and compromises. The American Journal of Psychoanalysis, 60, 293-306. doi:10.1023/A:1001929922264

[57] Craig, W.M. (1998) The relationship among bullying victimization, depression, anxiety, and aggression in elementary school children. Personality and Individual Difference, 24, 123-130. doi:10.1016/S0191-8869(97)00145-1

[58] Ollendick, T.H. and Hersen, M. (1993) Handbook of child and adolescent assessment. Allyn and Bacon, Boston. 